\title{
Pedro Claver, esclavo de los esclavos
}

\author{
Pedro Trigo, \\ Centro Gumilla, \\ Caracas, Venezuela.
}

Pedro Claver es un caso extremo de solidaridad, tanto por lo que realizó como por la perspectiva desde la cual lo llevó a cabo. Treinta y ocho años dedicado en cuerpo y alma a los esclavos, en el puerto de Cartagena, con altísima eficiencia y contentamiento de los destinatarios, es vivir una vida hasta el extremo. Pero más aún lo es vivirla "desde el reverso de la historia", es decir, perteneciendo a los esclavos. Pedro Claver se expropió a sí mismo para pertenecer a los expropiados de su derecho de disponer de sí.

La legitimidad de la esclavitud, en una sociedad cristiana, se amparaba en la distinción entre alma y cuerpo. El alma de los esclavos segura siendo libre y pertenecía a Dios; el cuerpo, es decir, la fuerza de trabajo, estaba enajenada, ya que pertenecía al amo. Esta separación, literalmente diabólica, no aparecía como tal por el dualismo de la cristiandad, agudizado en el postrento. Para pertenecer a los esclavos, Claver mortificó su cuerpo para que viviera casi de forma exclusiva como símbolo espléndido del amor que Dios les tenía. Difícilmente encontraremos un santo que haya negado tanto su cuerpo, $y$ es seguro que no habrá otro que haya abrazado y acariciado tanto a tanta gente con tanto amor.

La relación entre solidaridad y cuerpo es un tema crucial, en la época postmoderna, más aún, es un avance respecto de la modernidad. El cuidado es una actitud básica de nuestros tiempos. El cristianismo, desde su irrenunciable perspectiva creatural, asume esta perspectiva, pero dialectizándola. El caso de Claver, desde otra época, sin duda, puede arrojar mucha luz sobre el modo de encarar vitalmente este tema, desde el seguimiento de Jesús de Nazaret. 


\section{Vida $y$ fuentes}

\section{1., Bosquejo biográfico}

Claver nace en Verdú (Lérida), en 1580. Después de estudiar en su ciudad natal, lo enviaron sus padres a Barcelona, en cuyos Estudios Generales hizo cuatro años de gramática y uno de retórica. En 1602, entra en la Compañía de Jesús. Hizo el noviciado en Tarragona con extraordinarias muestras de fervor. De allí lo envían a Gerona, donde estudia un año de humanidades, y a Mallorca, en 1605, para estudiar filosofía. Allí, en el colegio de Montesión, es clave para su vida el encuentro con el hermano Alonso Rodriguez, quien llevaba largos años de portero y estaba en su ancianidad. El superior le da permiso para hablar con él un cuarto de hora diaria. Él le inculca la devoción, la humildad y la mortificación, así como la vocación misionera. El hermano le entregó un cuaderno de apuntes espirituales, que él leyó asiduamente, a lo largo de su vida y que, al enfermar, legó, con el permiso del General, al noviciado de Tunja.

A finales de 1608 , regresa a la península, habiendo pedido ya ir a misiones, y en efecto, en 1610, cuando comenzaba su segundo año de teología, lo envían a América. Es significativo que se embarca solo, en un barquito con pocas condiciones de navegabilidad, pero llega sin novedad a Cartagena. De allí lo mandan a Bogotá, donde le van a enseñar teología. La estudia de 1612 a 1615 , culminándola exitosamente con el examen ad gradum. En sus exequias, el vicario general de la diócesis de Cartagena, que la gobernaba por estar la sede vacante, dio un testimonio muy laudatorio de los tiempos en que ambos estudiaron juntos, alabando de forma especial su inteligencia e integridad.

Ese mismo año fue destinado a Cartagena, donde recibió el sacerdocio, en 1616. Se inició en el trabajo con los esclavos con el padre Alonso de Sandoval, que el año 1617 era llamado a Penú, hasta 1620, recayendo todo el peso sobre el neosacerdote Claver. Sandoval llevaba en Cartagena desde 1605 y permanecerá en el apostolado de los negros hasta su muerte, en 1652. En 1623, concluyó su tratado De instauranda aethiopum salute', el único tratado sistemático sobre la evangelización de los negros, inspirado en el De procuranda indurum salute, de Acosta. En él sobresalen a la vez la enudición y la capacidad para visualizar situaciones y sistematizar experiencias. Fue el maestro de Claver, quien sigue sus métodos y su esplritu, personalizándolos. En abril de 1622, Claver hizo la profesión solemne. En ella estampó después de su firma la fórmula que definió su vida: Petrus Claver, aethiopum semper servus.

Dice Astrán, en su bosquejo biográfico, que los jesuitas "le miraban como a un pobre hombre que no servía para otra cosa sino para lo que estaba haciendo:

1. Alonso de Sandoval, Un tratado sobre la eselavitud, Alianza Universidad, Madrid, 1987. 
esto es, para catequizar a los negros bozales que desembarcaban en Cartagena y luego eran distribuidos por otras partes de América"2. Confirma su apreciación, entre otros datos, con los informes secretos que enviaban a Roma los superiores. El de 1616 dice asf: "P. Pedro Claver. ingenio, mediano; juicio, menos que mediano; prudencia, corta; experiencia de los negocios, corta; aprovechamiento en las letras, mediano; talento; sirve para predicar y tratar con indios". En los de 1642, dice el historiador, "el ingenio, el juicio, la prudencia y la experiencia llevan siempre el calificado de mediocris; solamente se lo llama insigne en el ministerio de catequizar a los negros. En el catálogo de 1649 varian poco las calificaciones, con la diferencia de que el ingenio es bueno y la prudencia pequeña, exigua"'. Es un hecho que nunca es propuesto para superior, ni se le consulta nada, y eso que había una gran penuria de padres profesos y, por eso, de superiores. El único cargo que desempeña, además de su dedicación a los negros, es el de prefecto del templo.

Da mucho que pensar por qué fue tan poco estimada una persona tan notable por muchos motivos. Algo contribuiría el arte que tenía para ocultar todo lo bueno y para rebajarse siempre. Aunque ése tenía que haber sido más bien otro motivo de estima, en una época en que tantos ambicionaban la profesión solemne y los cargos. En este contexto, es significativa de su actitud la carta que dirigió al General, pidiéndole que no le diesen ningún grado, sino que lo mantuviesen con los votos del bienio, después del noviciado. El General le respondió expresándole que se edificaba de su propuesta, pero que se mantuviese indiferente a lo que determinase la Compañía.

Se dice que era mediocre en los negocios; pero en asunto de los esclavos, con la logística tan complicada que requería, se desempeño perfectamente bien, y lo mismo puede decirse de la atención al leprocomio o a la organización de la cuaresma y la pascua. Para él era fundamental, por ejemplo, disponer de intérpretes para cada lengua, aunque consta que él hablaba la general de Angola. Debió tener dificultades para disponer establemente de ellos, y por eso recurri6, en 1626, al General para que se compraran y se los dedicara en exclusiva a esta misión. El General le respondió, en 1628 apoyándolo entusiásticamente y encargando al Provincial que se dedicaran sólo a su servicio los ocho esclavos que requería.

Creo que la clave del problema estaría en el juicio o la prudencia. Para no pocos jesuitas, y entre ellos los superiores, su carencia en este punto tan crucial era tan grave que lo volvía no apto para la Compañja. Esta discusión nos intro-

2. Historia de la Compañía de Jesús en la Asistencia de España, Razón y Fe, Madrid 1916, vol. V, p. 482.

3. Ibid. 
duce en la entraña del ministerio de Claver. Por eso, la dejaremos para el final, después de haber dado los elementos que están en juego.

Ấcabaremos el esbozo de su vida diciendo que enfermó de una epidemia muy mortf́fera, que se desató en 1651 , en la ciudad, y al regresar de la misión, que emprendía todos los años, en pascua, por las haciendas, vino con un temblor en manos y pies que, al poco tiempo, le impidió decir misa e incluso mantenerse en pie. De todos modos, con ayuda de sus fieles intérpretes, continuó como pudo asistiendo a los leprosos y a otros ministerios, hasta que murió, en 1654. En su lecho de enfermo tuvo la alegria de escuchar el relato de la vida de su maestro, el hermano Alonso Rodríguez, escrita por Francisco Colín, en 1652. Su funeral constituy6 una verdadera apoteosis.

\subsection{Características de las fuentes}

Estudiaremos a Pedro Claver a partir de las actas de los procesos de beatificación y canonización ${ }^{4}$. El estudio será, pues, un análisis de textos, enmarcándolos en la época, que es de decadencia española y de consolidación de la América hispánica como América criolla. El ambiente cultural se caracteriza como barroco americano, que expresa ante todo una sensibilidad. El ambiente religioso es el postrento americano, y, dentro de él, el de la piedad popular barroca, como ocurría en la Compañáa de Jesús, tal como lo había configurado el General Aquaviva, como expresión extrema y sobresaliente de la contrarreforma.

Como todo material de este tipo, hay que tener en cuenta que las preguntas que aparecen en las actas configuran un prototipo de santidad que funciona como parámetro. Esto quiere decir que los que dan testimonio (y lo dan porque creen en la santidad de esa persona) deben demostrar a la Santa Sede que cumple con los requisitos que ella pone para declarar santa a una persona. Si se les hubiera dejado testimoniar libremente, saldría a relucir tanto lo que les impactó de la persona como su propio paradigma de santidad. De este modo, en cambio, deben aceptar el modelo propuesto y medir por él a la persona.

Esto opera un desplazamiento de paradigmas, y desde este esquema, la historia no es reveladora de lo que es, en una época, seguimiento eximio de Cristo, sino confirmación de que sí existen en ella ejemplares de los prototipos establecidos por la Santa Sede. La novedad del Espíritu queda opacada, la adecuación del seguimiento no es tal, porque se pone entre paréntesis la novedad de la historia y la del seguidor de Cristo. Sin embargo, a pesar de la rigidez del esquema, no puede menos de relucir la genuinidad del santo, si en verdad lo es, y esto es tanto más notable cuanto que el cuestionario no la busca. En el caso de Claver, esto resulta muy evidente: hay preguntas sobre las que apenas dicen nada los testigos,

4. Splendiani y Aristizábal, Proceso de beatificación y canonización de San Pedro Claver, Centro Editorial Javeriano, Bogotá, 2002. 
y lo dicen un tanto genérica e incluso forzadamente, mientras que en otras, los testimonios forman una verdadera avalancha, por el volumen. El contenido, además, es muy concreto y trasmite la honda emoción que el santo dejó en ellos.

El otro problema de este tipo de material es que no da pie para rastrear el proceso de la persona, es decir, cómo ha llegado a esa plenitud cristiana, ya que se parte de su estado de santidad. Ese no tiene por qué ser el caso de Claver, los testigos son todos de Cartagena, y hablan de él desde sus treinta y seis años de edad en adelante, cuando ya era sacerdote y estaba dedicado al único ministerio que desempeñó a lo largo de su vida.

Esto no sólo impide el análisis genético, sino también el estructural. Como los testigos deben ceñirse al cuestionario previo, se tocan cuestiones en las cuales la persona no era relevante, mezcladas con otras en las que sí lo fue. De este modo se dificulta extraordinariamente ver los ejes estructuradores de su vida, y la figura que ésta compone. No sólo eso, incluso la descripción de su ministerio y de acontecimientos relevantes no se recoge en su integralidad pluridimensional, sino que se vuelve a ellos una y otra vez, y cada vez desde una virtud del santo: su deseo de propagar la fe, la caridad para con los projimos, la atención a los enfermos, la mortificación...

En el material que recoge la edición que seguimos, la homogeneización de los testimonios alcanza cotas elevadísimas, fruto, tanto del estado de opinión que se formó entre sus admiradores y devotos, como de la adaptación de los traductores al italiano y al latf́n, que mostraban así cómo el candidato a santo pasaba el examen, ya que la opinión era coincidente y general. También hay que tener en cuenta que no leemos los testimonios originales, sino la traducción al castellano de la traducción que se hizo de los testimonios originales al lat́n y al italiano para uso de la comisión vaticana.

En particular, habría que mencionar la mano del hermano Nicolás González, que conoció al santo por más de veintisiete años, cinco antes de entrar a la Compañía y veintidós como religioso, que fue sacristán de la iglesia, cuando Pedro Claver era su prefecto, y que acompañó casi siempre al santo. Debía hacerlo uno, por la llamada "regla del compañero", según la cual un jesuita no podía estar solo, cuando salía de casa, y el encargado de acompañarlo era ordinariamente él. El hermano profesaba a Pedro Claver un inmenso cariño y admiración, que confiesa de modo expreso, en varias ocasiones; y a su vez, el santo le daba plena confianza.

Su testimonio es tan amplio que ocupa 130 pliegos, en el legajo original, y además, no se restringe a la mera descripción de la persona de Claver, sino que demuestra que habla comprendido tanto la lógica y estructura de sus ministerios como los móviles más íntimos del sujeto. Por eso, él es la base para cualquier vida que quiera escribirse sobre Pedro Claver. Además de eso, puede presumirse 
que influyó en el testimonio de los negros intérpretes. No significa eso, en modo alguno, que induća su testimonio, pues ellos profesaban al santo un cariño persenalísimo y una extrema veneración, y a la vez, se ve que dominaban su oficio, pero sí podía estar influyendo el testimonio, ordenándolo y dándole forma.

Por si esto fuera poco, el hermano Nicolás González actuó, en la última parte del proceso, como procurador de la causa. Su testimonio es muy consistente y convincente, porque no sólo ofrece un caudal impresionante de datos, sino porque los comprende e interpreta de forma convincente, de tal modo que de ellos mana la figura viva del santo y, más aún, el misterio de su vida. Que su testimonio es fehaciente, se prueba porque es corroborado, tanto por numerosos datos complementarios como por apreciaciones de personas independientes y con autoridad, que enriquecen mucho el cuadro que compone el hermano, pero sin cambiar nunca la clave.

Los testigos son variadísimos: tanto varones como mujeres, de todas las edades, estados de vida, condiciones sociales, razas y culturas. Componen un conjunto los hermanos jesuitas que vivieron con él y sus intérpretes esclavos negros: son los colaboradores pernnanentes de su apostolado y testigos continuos e íntimos de su vida. Otro está formado por devotos y devotas de la Compañía de Cartagena, que lo trataron de forma familiar. Entre estos, es relevante mencionar a los devotos y devotas particulares del santo, que le pedían ayuda espiritual y que lo ayudaban, a su vez, de modo asiduo para su apostolado con los negros y los enfermos. Otro conjunto significativo es el de los religiosos de san Juan de Dios y otras personas, ligadas a los hospitales que lo trataron mucho, especificamente, en ese medio. Otro grupo, con una perspectiva muy concreta, son los vecinos de Cartagena, entre los que cabe mencionar a los sacerdotes y religiosos de otras órdenes, a las autoridades, a los nacidos allf y que lo conocieron desde niños y a mucha gente popular, entre ellos enfermos y pobres a los que socorria habitualmente y a los que también recurría para ayudar a otros.

Una ausencia en extremo significativa son los padres jesuitas. En la edición de las actas no aparece ninguno, bien porque no testificaron, bien porque la traductora (una historiadora italiana) no juzgó relevante nada de lo que dijeron, y de hecho, no traduce todos los testimonios para no alargar tanto el texto, ni hacerlo demasiado reiterativo. Tal vez para paliar esta ausencia tan escandalosa, el traductor oficial al latín y al italiano llama reverendos padres a los hemnanos jesuitas que testifican. Un hecho que, en parte, explica esta omisión tan llamativa es que en la peste que hubo tres años antes de la muerte del santo murieron nueve del colegio de Cartagena. Además, habría que mencionar al padre Diego Ramírez Farina, a cuyo cuestionario se refieren constantemente los testigos. Este padre llegó al colegio para continuar el apostolado del santo, quince días antes de su muerte. Claver, que estaba muy enfermo, se emocionó con esta noticia, y de 
lo contento que se puso, bajó a besarle los pies y lo recomendó a una devota suya como confesor ${ }^{6}$. Asi, pues, aunque indirectamente, este padre sf intervino, testificando as que lo tenfa por santo, insistimos en que casi no vivió con él.

\section{Apostolado de san Pedro Claver}

\subsection{Dedicación a la salvación integral de los negros}

Desde los testimonios que poseemos, parece claro que la clave de la vida de Claver es la consagración a los negros como expresión de su consagración a Dios. En efecto, en la fórmula de su profesión escribió que se dedicaba a la salvación de los negros ${ }^{7}$ que se hacía esclavo de los esclavos para siempre. Quiero insistir que, en su caso, esa consagración es un documento personalísimo: pretende ser la expresión cabal de la opción fundamental, tomada después de un largo proceso de decantación de la voluntad de Dios sobre su vida y de liberación de su libertad para podérsela entregar efectivamente. Pues bien, la fómmula de los votos no le pareció suficiente para expresar su consagración personal y añadió, como lo más genuino y auténtico, en lo que desembocaba todo lo demás, su entrega a los negros.

Esta entrega fue comprendida y vivida como una expropiación de sí y una pertenencia a ellos. Esta pertenencia dio cauces y contenido a su vida, la salvó y plenificó, además de que dio vida a los negros: fue fecunda. Pero, no lo olvidemos, fue una consagración religiosa, formó parte de su consagración a Dios. Para Claver, esto no significaba ninguna mediatización ya que, para él, era obvio que el bien de los negros era su salvación integral: su vida de hijos e hijas de Dios, que implicaba una vida virtuosa y provechosa, pero, antes que eso, que vivieran sanos y que fueran respetados.

Así, pues, para Claver querer a los negros -0 querer ayudarlos - y querer su salvación, no era de ningún modo un dilema, sino que era una misma cosa, porque la salvación que él proponía no era impersonal, sino personalizada, aunque tuviera elementos objetivos, como el aprendizaje de la doctrina cristiana, el bautismo y, luego, la confesión, la misa y la vida virtuosa Pero el núcleo era la oración, la relación personalizada con Dios y con Jesús, con la Virgen y los santos, y la vida, que dimanaba de ahí. Tampoco había ninguna dicotomia, porque buscó su salvación, a través de una relación tan personalísima, que todos los testimonios subrayan que amaba a los negros y los trataba como si fueran su familia, sus hermanos e hijos ${ }^{8}$.

5. Cfr. Proceso, p. 376.

6. Cfr. Proceso, p. 397.

7. Cfr. Proceso, p. 84.

8. Ibld., pp. 87, 114, 175, 182, 202, 218, 223, 247, 253, 254, 261, 268, 463, 471, 475, 484. 
Por tanto, en nuestro ańlisis, vamos a partir de este apostolado, tanto con los que desembarcan provenientes de África y van a ser vendidos o transportados hacia el sur, como con los de la ciudad de Cartagena, como con los que vivían en las haciendas de la costa y de los ríos.

\subsection{Apostolado con los negros bozales}

\subsubsection{Recibimiento y primeras atenciones a los que llegaban}

Como marco, la referencia obligada es el De instauranda Aethiopum salute, de su maestro y compañero Luis de Sandoval, que murió dos años antes que él, después de cuarenta años de ministerio con los negros, en Cartagena. El describe de forma minuciosa cómo son capturados los esclavos, cómo hacen la travesía, en qué estado llegan a Cartagena y cómo son vendidos?. Son descripciones escalofriantes. Los testimonios las corroboran abundantemente, en lo que respecta a cómo llegan los negros y cómo son puestos en cuarentena. De los testimonios se deduce que en cada lote siempre había un grupo de enfermos y que enfermaban por las condiciones de la travesfa ${ }^{10}$ y que nadie los atendía. El encerramiento en las bodegas del barco, la humedad, el hacinamiento, la inmovilidad, la mala comida, los excrementos acumulados llevaba a que contrajeran enfermedades contagiosas, tanto de la piel y luego de la came (llagas infectadas y tumores), como de las vías digestivas y se supone que también de las respiratorias. En esas condiciones, el hedor tenía que ser absolutamente insoportable. Los testimonios abundan en las llagas, la pus y la carne que se caía a pedazos, además, de las frecuentes diarreas. El hedor y el temor al contagio aislaban a los enfermos. En las casas en que los tenían en cuarentena los mantenían sin atención médica y en desnudez, sin ninguna medida profiláctica.

Sandoval trata minuciosamente lo relativo al modo de catequizarlos y administrarles el bautismo", y en particular, la dedicación de los jesuitas a este ministerio ${ }^{12}$. En el texto, los testimonios que describen el apostolado de Claver, en esas primeras semanas, están distribuidos en diversas preguntas. La primera, sobre la administración del bautismo e instrucción a los negros infieles ${ }^{13}$; la segunda se refiere a su celo por la salvación de las almas ${ }^{14}$; la tercera, a la caridad con los enfermos ${ }^{15}$; la cuarta, a la caridad ${ }^{16}$.

9. Alonso de Sandoval, Un tratado sobre la esclavitud, pp. 142-154, 231-247.

10. Ibrd., p. 218.

11. Ibrd., p. 363-503.

12. Ibid., pp. 505-614.

13. Ibid., pp. 84-124.

14. Ibid., pp. 208, 210-225, 228-229.

15. Ibid., pp. 234-236, 254-256, 259-262, 293-294.

16. Ibid., pp. 323, 329. 
Al saber que venía un barco, recibía tal alegría que decía misas por el que le daba la noticia. Y asf, deseosos de que se las aplicaran, iban rápido a avisarle los primeros que se enteraban. Él averiguaba de qué naciones eran y conseguía intérpretes, si ya no los tenía, incluso mandándolos a buscar, fuera de la ciudad y pagándoles a ellos o a sus amos lo que le pidieran. Con el tiempo, consiguió un cuerpo completo de intérpretes, unos dieciocho, no pocos multilingües. Recogía limosnas entre sus devotos, y con los intérpretes, iba al mercado a comprar regalos para llevarles, y con ellos se dirigía, en barca, a los barcos.

Al llegar, por medio de los intérpretes, les daba la bienvenida, abrazando y acariciando a cada uno. Les decía que estaba allí como padre de todos. Les insistía que no iban a matarlos, sino a servirse de ellos, y que, si se portaban bien, también se portarian bien con ellos. Se extendía en estas razones y en esas pruebas de amistad porque, como confirman abundantemente los testimonios, en su tierra les hacían creer que los matarían para sacarles la manteca y pintar con su sangre los barcos. Por eso, venían llenos de desesperación y se dejaban morir de hambre o se arrojaban al mar. Les decía que Dios los habra trardo para que lo conocieran y para hacerlos sus hijos.

Averiguaba si había enfermos graves o recién nacidos en peligro, se dirigía donde ellos, limpiándolos, aliviándoles con lo que había traído al efecto y dándoles algunas golosinas y de beber. Luego, les preguntaba si habían recibido el bautismo. Si no lo habian recibido, por medio de los intérpretes los preparaba lo mejor posible y con la solemnidad del caso, los bautizaba. A los ya bautizados, los instruía. A todos les ponía los óleos.

Y volvía a hablar al conjunto de los negros del barco con muestras de gran cariño. Pedía a los capitanes y a los amos que desembarcaran primero a los enfermos, y él y los intérpretes les ayudaban para que sufrieran lo menos posible, en el traslado. Al desembarcar, mandaba nuevamente a los intérpretes con regalos para que les dieran la bienvenida y les aseguraran su compañia y ayuda. Cuando fue mayor y su salud se quebranto, los superiores le prohibieron ir a los barcos; entonces, enviaba con esas instrucciones a los intérpretes y él salía a recibirlos al muelle. Se aseguraba que se trasladara con el mayor cuidado a los enfermos y él mismo ayudaba.

Cuando estaban en las estancias que les habían reservado, repetía lo mismo, abrazándolos, consolándolos y distribuyendo regalos. Gastaba mucho tiempo cada día con los enfermos, atendiéndolos personalmente. Todos ponderan que lo hacía como si fueran de su familia, con todo amor y delicadeza y con suma paciencia y eficacia. Nunca daba la impresión de que se estaba mortificando, aunque los intérpretes, sólo por respeto a él, toleraban permanecer con los enfermos. Todos insisten en que parecía impasible, de bronce, como si no fuera de este mundo, ya que parecía no afectarle ni el aspecto repugnante, ni el hedor, ni las enfermedades contagiosas. Subrayan que el rostro se le trasfiguraba de tanto cariño y 
gusto. También insisten en el cuidado que tenía con los intérpretes y acompañantes para que no se contagiaran. No soportaba que los enfermos no soportaran su piopio hedor, y hacfa infusiones de yerbas aromáticas y arropaba al enfermo en su manteo para que le envolviera más el aroma. Era diestro en remedios, y asf no sólo mostraba una voluntad de oro, sino eficacia.

No es fácil captar lo que sentirfan los negros. Varios intérpretes dicen que ellos habian llegado con ese desfallecimiento vital y esa angustia, y que la actitud del padre los ganó para siempre. Los habran capturado con violencia, los habfan vendido como mercancía. Como tal, los habfan trasportado sin ninguna consideración. Y cuando esperaban ya la muerte, aparece este personaje con tal capacidad comunicativa, en una onda radicalmente diferente. No les serla fácil procesar lo que estaba ocurriendo, pero por todos los testimonios, consta que se abrian al ofrecimiento amistoso de Claver, que su actitud era fehaciente.

\subsubsection{Instrucción en el cristianismo}

En las estancias donde los tenían en cuarentena, esperando a que se recuperasen, para venderlos o trasladarlos al sur, comenzaba el proceso de instrucción, en el cristianismo. Procuraba ropas para los varones y sobre todo para las mujeres, pues todas venían desnudas. Ponfa a un lado a los varones y al otro a las mujeres y los enfermos aparte con la comodidad posible. Hacía traer sillas de mano para que se sentaran los intérpretes y para que esa muestra de autoridad animara a los esclavos a hacerse cristianos. Los instruía con mucha mímica, logrando que los negros participaran con todo entusiasmo. Les hacía repetir los gestos muchas veces, hasta que los incorporaban. También les mostraba cuadros muy gráficos, en los que aparecían negros con caracterizaciones deseables o repulsivas, según lo que quería inculcar. Alternaba lo grupal y lo individualizado, ambas dimensiones personalizadas.

La instrucción tenía cinco puntos: la Trinidad, la encarnación, la pasión y muerte en cruz, la resurrección y la resurrección universal para el juicio final. Les explicaba con ilustraciones, con comparaciones, con narraciones. Tenía también una lámina con un alma en llamas, atormentada por los demonios. El padre explicaba que era el alma de un negro muerto sin bautismo. Por eso, debían agradecer a Dios por haberlos llevado a tierra de cristianos, donde se bautizaran, haciéndose hijos de Dios y entraráan en la Iglesia. Pero lo más sustancioso de su instrucción era sacar el crucifijo del pecho y decir cómo el Señor se había puesto en esa cruz para pagar por nuestros pecados y salvar asi al género humano. Si querían ser sus hijos, les debía doler haber vivido sin conocerlo y sumidos en la idolatría, la ebriedad, la lujuria y otros pecados. Por eso, tenfan que arrepentirse de corazon y pedir perdón a ese Señor. El padre repetía una y otra vez, mostrándoles el Cristo y dándose golpes de pecho: "Jesucristo, Hijo de Dios, tú eres mi padre y 
mi madre, yo te amo mucho, me duele en el alma haberte ofendido"17. "Era tanto el fervor con que decfa esto, que quedaba largo tiempo en suspenso y como fuera de sí, derramando con gran ternura muchas lágrimas"lis. Los negros también se enternecían y golpeaban el pecho. Luego, les decía que, asi como la serpiente muda de piel, ellos debfan arrancar de sí la idolatría y los vicios. Y mientras lo decía, hacía ademán de que se quitaba la piel de cada parte del cuerpo, "imitándolo todos en esta acción con tanto fervor que parećá que se despojaban verdaderamente de su piel y la arrancaban de sí, y la escupían en señal de que se despojaban del antiguo Adán y de sus pasiones y vicios, y se vestían del hombre nuevo, Cristo, y de sus virtudes, profesando la ley evangélica que él enseño"19.

Estas instrucciones, las repetfa muchos dfas, muy personalizadamente y les explicaba lo que es la fe y les enseñaba a hacer actos de fe. También los animaba a que tuvieran esperanza de verlo y gozarlo en el cielo; les decia "lo que en este mundo tocaba a la esperanza con palabras tan ardientes y vivas razones que parecía que les encendiera los ánimos e inflamara sus almas con seguras esperanzas de la gloria que habían de alcanzar por medio del bautismo"20. Luego, los llevaba a actos de amor de Dios y les decla también "cómo por Él y por su amor se debfan amar mucho unos a otros sintiendo por cualquier prójimo o compañero suyo el mismo afecto que se tenían a si mismos"21. Y decfa ejemplos muy concretos como compartir la comida, deponer las enemistades que tenían en su tierra o las que surgieron en el viaje, renunciar a venganzas. $Y$ pedía que los que hablan sido enemigos se perdonaran y se abrazasen, "tratándose como hermanos e hijos de Dios"22. Conclufa diciendo que en la caridad se contenfa el resumen de toda la ley de los cristianos.

No parece muy pedagógico empezar por la Trinidad, ni omitir el Creador, la creación y su espíritu, que anima todas las cosas, ya que considerar todo creación de Dios y al espíritu animándolo todo era el lazo de unión con su religión africana. Omitir la vida de Jesús, pasando de la encarnación a la pasión no ayuda a captar el cristianismo como la religión de la humanidad. Si tiene sentido la insistencia, tan paulina, en el amor de Jesús, que reluce en la cruz, y cómo la respuesta es no crucificarlo con nuestros pecados y arnarle. Él es nuestro padre y nuestra madre. Un Dios humanado y crucificado si podía ser captado por connaturalidad, por estos condenados de la tierra. El que el amor, el de Jesús y el de ellos, es decir, la relación personal por excelencia, llevara la voz cantante,

17. Ibid. p. 92.

18. Ibid.

19. lbrd. pp. 92-93.

20. Ibid., p. 93.

21. Ibid., p. 94.

22. Ibld. 
tenía que emocionarlos, aunque les tenía que resultar no fácilmente verificable, fuera de la actitud del padre y sus ayudantes. La situación tan extrema en la que estapan sf era propicia para un renacimiento. De este modo, tenían un lugar y una dignidad, en ese mundo al que llegaban como condenados. Adquirían una interioridad, que era un modo de libertad. El que ese desconocido, que no les pedía nada, sino que les daba cosas necesarias y gustosas y cariño, les dedicara tanto tiempo, era la mayor buena nueva, ése era propiamente el evangelio. Ése era el sacramento de que Dios los amaba y los quería hacer sus hijos. Sin embargo, al irse el padre, todo quedaba igual de deprimente, el trato era cruel y despersonalizado. No era fácil componer el mundo del padre y su nueva cotidianidad.

\subsubsection{Bautizo}

La ceremonia del bautizo trataba de ser lo más solemne y grata posible, pero también lo más gráfica y personalizada. De ahí, el cuadro del negro sin bautizar en el infierno y el negro hermoso, lavado por el agua del bautismo, que viene de la sangre de Cristo en cruz. De ahí, las preguntas, que debía responder cada uno: si querfa ser bautizado, de quién era esa agua (de Dios), de quién quedaba hijo, recibiéndola (de Dios), dónde iŕa con aquella agua (al cielo). "Todo encendido y llameante de amor de Dios (dice uno de los intérpretes negros) lo bautizaba derramando el agua sobre su cabeza con un jarro de barro vidriado. En seguida ordenaba que se le pusiera al cuello una medalla"23 de plorno con Jesús a un lado y María al otro. "Después de haberlos bautizado a todos, se ponía de rodillas frente al altar y permanecía en oración por un largo rato, dándole gracias a Dios por los favores que le había hecho en haberse querido servir de él como de instrumento para que los infieles recibieran el agua del bautizo. Abrazándolos a todos, los despedía diciéndoles que recordaran cómo eran antes de recibir el santo bautismo, porque ahora estaban en gracia de Dios, eran hijos adoptivos suyos y herederos de la gloria"24.

Realmente, la escena es grandiosa. Según la teología de la época, que negaba la salvación a los que estaban fuera de la Iglesia, bautizar a los infieles era lo más sublime que se podía hacer. Pero aun hoy, aunque nosotros creamos que Jesús en la pascua ha derramado el Espíritu en todos los corazones, saber todo lo que el padre explicaba, creerlo y consagrarse a ello, ¿no es también lo más grandioso que puede suceder a una persona? ¿No es comprensible que a un hombre de fe como Claver le colmara de felicidad que Dios lo hubiera elegido para que llevara a esta relación con él a cientos de miles de personas, y precisamente a unas personas no tratadas como tales que, por eso estaban en trance de despersonalizarse, y que, sin embargo, eran en realidad los predilectos de Dios?

23. Ibrd., p. 107.

24. Ibid. 
Sin embargo, hay un punto que para los negros tenfa que resultar muy amargo: el que los antepasados estuvieran en el infiemo. Para ellos, los ancestros son sagrados: les han dado vida, han vivido y muerto para darles lugar a ellos. Se sentían ligados a ellos, por lazos sagrados, por el espíritu. ¿Cómo podían creer que por no conocer a Jesús sin culpa suya y por no estar bautizados, estarían en el infiemo? Está bien que se exalte de modo positivo la grandeza del bautismo, pero no que se denigre lo anterior. Fue el mismo problema que palpó Javier, en Japón. La diferencia es que allí eran libres, tenían voz, estaban en su casa y el padre era huésped suyo. Por eso, pudieron expresar a Javier esa tristeza, que él no pudo remediar. Aquí, los negros no tenían voz, no podían manifestar pesar y menos desacuerdo. Además, ¿cómo hacerlo respecto de la única persona que los recibra, les daba la bienvenida, les manifestaba su amor, les aliviaba en su estado tan desesperado y les introducía en ese mundo nuevo, colocándolos en un estado de dignidad, la dignidad de los hijos de Dios?

Al día siguiente del bautizo, volvía muy de mañana y les manifestaba que, como eran hijos de Dios, debŕan evitar ofenderle; pero que, como eran débiles, si pecaban, tenían como remedio la confesión. Les enseñaba la manera de hacerla y les decía que no tuvieran vergüenza de decir sus pecados, porque el confesor estaba en lugar de Dios y guardaría secreto. Durante muchos días los instruía sobre la confesión. También los días de fiesta los llevaba a la misa. "Y era tan fuerte el mal olor, que las mujeres españolas no lo podían tolerar y salían de la iglesia" ${ }^{2}$. Esto debra ser muy notorio, porque hay muchos testimonios al respecto.

\subsubsection{Despedida a los que seguían viaje hacia el sur}

Cuando sabía que algunos grupos debran viajar a otras partes ${ }^{26}$, sobre todo a Perú, iba a verlos y los animaba, diciéndoles que encontrarían buenos amos, que los atenderían bien y les darían vestidos. Les insistía que, si alguno enfermaba en el viaje, le llevaran al confesor. Les recordaba los mandamientos de Dios y de la Iglesia y les volvía a explicar que debían confesar con dolor y arrepentimiento de haber ofendido a Dios y propósito de no volver a hacerlo. Si no habra sacerdote, debran hacer un acto de contrición. Era el mismo que les enseñara al comienzo. Se los repetía hasta que lo supieran de memoria: "Jesucristo, Hijo de Dios vivo, tú eres mi padre y mi madre; yo te amo mucho, me duele en el alma haberte ofendido. Yo te amo mucho, mucho, mucho"zr. Todo esto se lo encargaba, encareciéndoselo mucho, al negro que los dirigía. "Finalmente hablaba a los capitanes y a los dueños, pidiéndoles que por amor de Dios tuvieran mucho cuidado de ellos y les dieran regalos en el viaje. Ellos se lo prometran y el padre avisaba lo referido a los negros para consolarlos y animarlos mucho. Y estando

25. Ibrd., p. 107.

26. Ibrd. pp. 97, 107-108, 117, 207, 224-225, 324.

27. Ibid., pp.116-117. 
ya cercano el viaje, un día o dos antes, iba a sus casas y les llevaba tabaco y algunos otros regalos"2s.

\subsubsection{Valoración de este ministerio}

Es importantísimo entender la teologfa de la época para comprender este ministerio, ya que el bautismo era de modo absoluto la puerta para llegar a ser hijo de Dios, y la confesión, la segunda tabla de salvación, si se habra pecado después, suplida por el acto de contrición, si no había confesor. Para Pedro Claver, como para nosotros, nada es comparable a la dignidad y dicha de ser hijo de Dios y de vivir y morir como tal. Por eso, este ministerio se tomaba tan en serio, que los negros llegaban a hacerse cargo de algún modo de la grandeza a la que habían sido llamados. Él los introducía con su devoción en el misterio y ellos participaban, a su modo, de él. De ahí, la gran alegria del santo.

Pero hay que enfatizar que el que Dios nos haya hecho sus hijos era para él la mayor manifestación posible de amor. Por eso, el amor humano de Pedro Claver a los negros era el sacramento del misterio, al que habran sido llamados. La verdad de este amor, su ingenio, su generosidad, su afecto, les hacfa ver que ese misterio era muy real. Por eso, la fórmula del acto de contrición, recitada por él con toda el alma, era la síntesis de todo. El que él fuera para ellos realmente su padre, su madre y su hermano, les hacía ver la verdad de que eran hijos de Dios. Esa profunda realidad le daba la fortaleza, la constancia, el ingenio, la temura. El estar absorbido por esa relación con los negros, hacia que el hedor, el peligro del contagio y la fatiga no hicieran mella en él. También consta que esta actitud impresionaba, no sólo a los vecinos de Cartagena, especialmente a los curas y a los oficiales reales, sino también a los que tenían a cargo a los negros: los dueños y capitanes.

\subsection{Atención integral a los negros residentes en la ciudad}

El segundo ministerio con los negros tenía que ver con la perseverancia de los ya bautizados, que vivían en la ciudad y en su contomo. A los primeros se dedicaba diariamente, pero de modo muy particular en la cuaresma, y a los segundos atendía durante varios meses, después de la pascua El resultado de este apostolado, según un sacerdote cartagenero, que conoció al padre, desde que tuvo uso de razón, es que "la experiencia ha demostrado que todos han perseverado en la fe primera que les enseño, cuidadosos de asistir a misa y de visitar los templos y ejercer la caridad. En particular tienen devoción de mandar decir misas por sus difuntos"29.

28. Ibid., pp. 108, 324.

29. Ibrd., p. 123. 


\subsubsection{Dedicación a ofrles en confesión}

Los textos sobre la atención en la cuaresma son muy abundantes ${ }^{30}$. Lo que hacía todos los días era confesar, desde que se abría la iglesia hasta las diez, los días laborables, y hasta las once, los domingos y fiestas. Entonces, decía misa, la última misa, para dar oportunidad a los ocupados. Muchas veces, estaba tan abstraído en este ministerio que habia que llamarlo para que fuera a decir la misa. Después de la accion de gracias, seguía confesando, hasta que se cerraba la iglesia, y luego, a las dos, cuando se abria, segufa hasta las seis de la tarde. De día, confesaba sobre todo a negras, y en una sala de recibo, a los negros, hasta las nueve de la noche, hora en que se cerraba el colegio. Tenía en la capilla, cerca de su confesionario, cuadros devotos del infiemo, el purgatorio y el cielo, y de la pasión, incluida la crucifixión. El padre hacía pláticas fervorosisimas con los tres primeros cuadros, tanto que "no sólo alzaban las voces conmovidos por la fuerza del dolor que sentían y por lo que el padre les decía, sino que también elevaban las manos, como queriendo pedir perdón y misericordia al cielo"3ı. Por último, se arrodillaba, y todos con el, "y les hacía un acto de contrición muy fervoroso. El modo como lo decía era ya suficiente para mover a contrición y dolor a los corazones más duros y empedernidos. A este acto, si bien el padre lo hacía sólo para los negros y negras de los que tenía especial cuidado, se acercaban para ofrlo este testigo y muchas otras personas españolas" ${ }^{132}$.

Como la iglesia era muy húmeda, por la cercanía del mar, ponía una tarima y tablas con esteras para que se sentaran mientras esperaban, y como se ensuciaban, él y los intérpretes las lavaban con frecuencia. A los viejitos y enfermos, él mismo les ayudaba a ir al confesionario y luego al altar y a ellos y a las que tenían que irse donde sus amas, les daba la comunión y después, remedios, galletas, plantas aromáticas y un traguito de vino, para que se repusieran y no desfallecieran por el camino.

Los testigos insisten mucho en la cálida humanidad con que los acogía, tanto que siempre recurrian a él. A la noche, se quedaba tan extenuado que tenían que llevarlo a peso al comedor. All comf́a plátano asado y pan untado en vino aguado, que, dice uno de los intérpretes, "comía tan poco que casi todo lo daba a este testigo que lo acompañaba" ${ }^{33}$. Cuando estaba muy cansado, pedía que le echaran unas gotas de vino en un pañuelo y lo olfa de vez en cuando. Sin embargo, algunas veces, llegó a desmayarse, en el confesionario.

30. Ibrd., pp. 101, 104-105, 118, 130-138, 167-168, 170-188, 199-201, 208, 216, 225 $227,230,347-348$.

31. Ibid., pp. 225-226.

32. Ibid., p. 226.

33. Ibid., p. 208. 


\subsubsection{Misa y procesión, en los días de fiesta}

Los domingos y días de fiesta, por la tarde, salía con un bastón rematado en un erucifijo y con una campanilla, que hacía sonar, convocando a los negros. Se formaba una gran procesión. Iban por las calles, cantando las oraciones. Precedra un estandarte rojo. También enviaba a los intérpretes a reunirlos. El punto de concentración era la plaza de la Yerba, que era donde se reunían ellos. All, se subía a una tarima y les preguntaba el catecismo y daba regalos a los que mejor contestaban. Luego, dos intérpretes lo decían todo, preguntando y respondiendo. Seguidamente, él les explicaba algunos puntos, que veía no entendían y les hacía una exhortación "más con fervor y devoción que con abundancia de razones y palabras"34. Luego, regresaban a la iglesia, cantando oraciones. All, "estando todos arrodillados y el padre Claver en medio de ellos, con voz tiema y afligida, les hacfa recitar el acto de contrición. Luego los despedía"3s.

En la mañana, ya dijimos que enviaba a los intérpretes a buscarlos para la misa de once. "A veces eran tan numerosos que no cabfan en la iglesia y era tanto el mal olor que exhalaban, que a veces vio este testigo cómo algunas damas españolas salfan huyendo de la iglesia; pero este olor era para el padre Claver de flores y rosas"

\subsubsection{Valoración de este ministerio}

Sin duda que en este proceder del padre pesaba que tenían que cumplir con el precepto de la Iglesia de confesar y comulgar. Pero el modo como lo hacía nada tenía de convencional. Él trataba realmente de que los negros y negras sintieran el amor de Dios y, al sentirlo, se dolieran de lo que le habían ofendido y procuraran de veras una conversión sincera. Él querfa inculcarles ese amor de Dios, que reluce sobre todo en su pasión. Sabra que ese proceso los dignificaba, los enaltecra. Quería, por todos los medios, que se vieran a si mismos como hijos e hijas de Dios. Por eso, los recibfa con un amor infatigable. Por ese ardiente deseo es verdad que su olor, por ser suyo, de sus hijos y hermanos, era de rosas. Por eso, salfa a buscarlos y ellos se dejaban encontrar y respondran a su solicitud. Esa dignidad les daba derecho a estar con los españoles, que en la iglesia no eran sus amos, sino sus hermanos. Ocupar ese espacio sagrado tenía que darles inmensa satisfacción. Claro que hubieran deseado que todos se quedaran; pero el que salieran las mujeres, expresaba también que reconocfan su derecho a ocupar ese espacio. Ocupar ese espacio sagrado se debra al ministerio de Pedro Claver. Experimentaban en él el amor maternal de Papa-Dios como fuente de reconocimiento social.

34. Ibid., p. 130.

35. Ibid.

36. Ibid., pp. 104-105. 
La ternura que perfumaba ese reconocimiento se echaba de ver en los obsequios que tenía para ellos, en el confesionario. Sólo un hombre santo podra llegar a comprender que esos regalos no sólo no profanaban el sagrado tribunal de la confesión, sino que eran la equivalencia más exacta del banquete que celebró el Padre, tras la vuelta del hijo pródigo. Éstos también venían de lejos, pero no por haber dilapidado la herencia divina, sino porque nadie se las habra revelado. Venían de sufrir el oprobio de la esclavitud de manos de quienes se profesaban cristianos.

Relucía tanto esta calidad trascendente, que también españoles, movidos a devoción, seguían el acto de contrición, en la capilla contigua al confesionario. Lo acompañaban los domingos a la tarde en la procesión con los negros, y aceptaban esperar muchísimo tiempo para llegar a confesarse con él. Y aguantaban el mal olor para asistir a esas misas, o se salían sin protestar, cuando no podian aguantarlo.

Esta ternura llegaba al colmo en el caso de los enfermos impedidos, a quienes mandaba a buscar, en sillas de manos, y luego, él mismo ayudaba con todo cariño a acomodar en la iglesia y a llegar hasta el comulgatorio, después de haberlos confesado. $\mathrm{Y}$ antes de devolverlos a sus casas, los obsequiaba con remedios, comida y golosinas, sin que faltara un sorbo de vino. Estos enfermos, tratados como señores, ¿cómo no iban a experimentar en Claver la misericordia y la ternura de Dios?

Dos aspectos me parecen especialmente dignos de notarse: la ocupación de los espacios públicos (calles y plazas), por parte de los esclavos, y la atención personalizada de las confesiones. Lo primero es una especie de reivindicación. Los invisibles, los que tenían que ceder el paso a todos, los que pasaban por esos lugares en oficios estimados como viles, iban marchando por ellas, con la frente en alto, llenando todo el espacio, sin hacer ningún trabajo, sino por devoción. Lo segundo es, en la práctica, lo mismo: aquellos que servían impersonalmente, que atendían a otros de abajo arriba, eran atendidos, preferidos, mimados por una persona que gozaba de gran autoridad. Esto los tenía que colmar de satisfacción. Tenían que entrever que el cristianismo era, en realidad, trascendente.

Esta relación personalizada llevaba a Claver a ver el estado de cada uno y a no contentarse con el cumplimiento formal del precepto, sino a emprender un proceso tal que llevara a la auténtica conversión. Por eso a los de vida desordenada no los absolvía durante la cuaresma, sino en la semana santa, después de haber constatado que los sermones y demás ejercicios de piedad les habran tocado el corazón. 


\subsection{Misión en pascua por las haciendas}

La pascua la reservaba para ir por las haciendas para que los esclavos pudierarn cumplir con la confesión y comunión anual ${ }^{37}$. Era época de lluvias y clima muy insano, a veces no habra camino e iba con el fango hasta la rodilla. A los pueblos iba en caballo, acompañado por un intérprete. Llevaba licencias para confesar, decir misa y casar.

En las haciendas, le ofrecían un cuarto de señores y él lograba que le dieran el peor de los negros o, más frecuentemente, el que ellos desechaban. Por lo general, estaba muy sucio y con ratas y murciélagos. Él ayudaba a limpiarlo y se quedaba en él. No dormía en la cama que le ponían, sino en una estera. Estaba confesando hasta las once, cuando decía la misa, para dar lugar a que asistieran los vecinos. Luego, se retiraba a su pieza. Uno de los hacendados declara que tenía que ir a llamarlo para comer: "muchas veces lo encontraba tan elevado, con la cara mirando al cielo y el misal abierto en la pasion que, si bien se le acercaba para verlo y llamarlo, el padre no se percataba ni se movía hasta que este testigo le hablaba diciendole que viniera a comer, que era tarde. Entonces no se excusaba, antes con mucha modestia se mostraba obediente, y doblando la hoja del misal se iba con este testigo"'38. Sólo comía un trozo de carne salada y arepa o casabe, y a la noche, plátano asado y agua. De lo otro que habra en la mesa, tomaba para dar a los esclavos. Y si le regalaban huevos o pollos, los aceptaba y se los daba al más pobre o mandaba prepararlos para los enfermos. Por la tarde, predicaba, catequizaba y confesaba. El intérprete declara que se lo comran los mosquitos, y que le insistra que los matara y el le respondió "que más bien le hacían un favor pues le extraían la mala sangre"39.

Quiero destacar la insólita libertad espiritual para colocarse de forma tan decidida, en el mundo de los esclavos, para comer lo que comían ellos y para disponer de lo de la mesa de los señores para darles a ellos. Y más todavia, para dedicarles a ellos, en la práctica, todo su tiempo, porque a los señores y, más en general, a los vecinos, sólo dedicaba la misa y la confesión y, si lo instaban demasiado, un momento en la mesa, ya que enseguida se levantaba, diciendo que tenía que ocuparse del negocio de los negros. Uno piensa que lo tendrían que resentir los amos. Pero los testimonios de que disponemos indican que, más bien, se quedaban muy edificados de lo que interpretaban como extrema humildad, y en el fondo, como no estar en las cosas del mundo, sino exclusivamente en las de Jesucristo, cosa que era cierta

Como no comía hasta pasado el mediodía y lo hacía tan parcamente y como segula en su ministerio hasta muy de noche, alguna vez se desmay6, pero al

37. Ibld., pp. 138-149, 177, 181, 183, 367-368, 371-372, 392-394, 416-417.

38. Ibld., p. 146-147.

39. Ibid., p. 142. 
volver en sí, no aceptó ningún reposo, ni regalo, y siguió en lo que estaba haciendo.

Atestigua su médico que "su mayor recreación y alegría era después de Pascua de Resurrección ir fuera de esta ciudad a las poblaciones de los negros" (p. 140). Éste fue su apostolado más duro, tanto que al regresar de uno de esos viajes, vino ya con la enfermedad de la que murió. Sin embargo, su instinto evangélico le hacía ver que lo más cercano a Jesús era ir en busca de los pobres para llevarles la única riqueza que tenía: Dios y Jesús como Padre materno y hermano misericordiosísimo. Se los ofrecia y los llevaba a corresponderles. Lo lograba, no sólo con sus fervorosísimas exhortaciones, sino sobre todo entregando, como Pablo, su propia persona junto con el evangelio. Su solicitud humilde, generosa, tierna, dedicada y fuerte era la certificación humana de que Dios y su Hijo se les entregaban de veras. El que viviera en su mundo y no en el de los amos, el que les hiciera saber a éstos que lo suyo era el negocio de los negros, el que les concediera a los de arriba el menor tiempo posible y se lo prodigara a ellos, el que comiera lo de ellos y les diera a ellos lo de los blancos, el que el enviado de Dios fuera de ellos, tenía que dejarlos gratificados, dignificados, confortados.

\subsection{El escándalo de dar la comunión fácilmente a los negros}

Quiero insistir en un aspecto muy significativo de su certero instinto evangelico. Dice el hermano Nicolás: "También observó este testigo que el padre Pedro Claver que con su gran devoción y fervor fue, no obstante, poco escrupuloso en dar licencia para que cualquier clase de personas comulgara, tanto españoles como negros e indios, cuando encontraba en ellas una capacidad mediana para poderla recibir. Exhortaba a todos generalmente a la frecuencia de la comunión, instruyendo con mucha diligencia a aquellos que no estaban aún dispuestos para recibir este Venerable Sacramento. Y tenía tan poco escrúpulo en esto que algunas veces era criticado por la mucha facilidad en conceder esta autorización a las personas, tanto negras como indias. $\mathrm{Y}$ a algunos religiosos de nuestra Compañía y otros de fuera, religiosos y seglares, respondía con toda mansedumbre, modestia y particular humildad, con la parábola del Evangelio de aquel rey que hizo el convite esplendoroso y habiéndose excusado algunos, ordenó a los sirvientes que condujeran al convite a los ciegos, locos y lisiados. $\mathrm{Y}$ añadía que adivinaran a quiénes se referfa: a los pobres negros, esclavos y abandonados de esta ciudad"40.

El conceder con facilidad la comunión a negros e indios fue criticado tanto por los de su comunidad como por otros religiosos y seglares. Él respondfa con la parábola del banquete y la aplicaba sin titubear a los esclavos y abandonados de Cartagena. Dar la comunión a indios fue una decisión de los primeros jesui-

40. Ibid., p. 79-80. 
tas, que Acosta tuvo que defender hasta plantearla al mismo Papa, que confirmó su derecho. Sin embargo, en una sociedad de castas, donde la comunión frecuente era para las almas selectas, no podía aceptarse que entre ellas se contaran esclavos. Si los esclavos son tan selectos, ¿qué argumento se puede esgrimir para que sean esclavos? Lo que es selecto para el Dios de Jesús no coincide con la jerarquía social. Eso en una cristiandad es muy difícil de tragar, en concreto. Pero, puesto el argumento por un hombre santo, no es fácil de rebatir.

Dar la comunión a los negros es el símbolo más delicado de lo inasimilable de la actitud evangélica de Pedro Claver. Nadie que lo viera preparándolos para la confesión y comunión podráa acusarlo de ligereza. Más bien, tendría que reconocer que ellos no se preparaban tan fervorosamente. El problema de fondo es por qué gastar pólvora en zamuros, por qué dedicar un esfuerzo tan cualitativo a los que no tenfan calidad, en vez de emplearlo en sujetos más respetables. Éste es el problema de fondo, que no era fácil plantear, ya que Claver respondía con el puro evangelio: el de la predilección de Dios y Jesús por los pobres.

Continuará con el análisis de su entrega a lo enfermos, a los presos y condenados a muerie, y de la fuente de su apostolado. 